Baptist Health South Florida

Scholarly Commons @ Baptist Health South Florida

All Publications

$7-2020$

\title{
Maxillary Occlusal Splint Following Segmental Mandibulectomy and Osteocutaneous Free Flap Reconstruction - A Case Report
}

Evan Rosen
Miami Cancer Institute, EvanRo@baptisthealth.net

Follow this and additional works at: https://scholarlycommons.baptisthealth.net/se-all-publications

\section{Citation}

Ann Maxillofac Surg (2020) 10(2):518-520

This Article -- Open Access is brought to you for free and open access by Scholarly Commons @ Baptist Health South Florida. It has been accepted for inclusion in All Publications by an authorized administrator of Scholarly Commons @ Baptist Health South Florida. For more information, please contact Carrief@baptisthealth.net. 


\title{
Annals of Maxillofacial Surgery
}

\section{Maxillary Occlusal Splint Following Segmental Mandibulectomy and Osteocutaneous Free Flap Reconstruction - A Case Report}

\author{
Allison G. Petty, Zain Uddin Ahmed, Amr A. Habib, Joseph M. Huryn, and Evan B. Rosen ${ }^{1}$ \\ Department of Surgery, Memorial Sloan Kettering Cancer Center, New York, NY, USA \\ ${ }^{1}$ Miami Cancer Institute, Miami, FL, USA \\ Address for correspondence: Dr. Evan B. Rosen, Miami Cancer Institute, 8900 N Kendall Drive, Miami, FL, \\ 33176, USA. E-mail: evanRo@baptisthealth.net \\ Received 2019 Nov 20; Accepted 2020 Apr 6. \\ Copyright : @ 2020 Annals of Maxillofacial Surgery \\ This is an open access journal, and articles are distributed under the terms of the Creative Commons Attribution- \\ NonCommercial-ShareAlike 4.0 License, which allows others to remix, tweak, and build upon the work non- \\ commercially, as long as appropriate credit is given and the new creations are licensed under the identical terms.
}

\begin{abstract}
Postsurgical malocclusion is a possible sequela of care following segmental mandibulectomy and osteocutaneous free flap reconstruction. Patient-specific factors may make surgical correction an impossibility. In addition, conservative occlusal adjustments may be insufficient for correction of the occlusion. An alternative approach for the management of severe postoperative malocclusion is to fabricate a maxillary occlusal splint, which establishes interocclusal articulating surfaces and facilitates mastication. The purpose of this report is to demonstrate the technique and utility of a maxillary prosthesis to correct posttreatment malocclusion in the oncologic patient.
\end{abstract}

Keywords: Fibula free flap, malocclusion, maxillary occlusal splint, oral rehabilitation, segmental mandibulectomy

\section{INTRODUCTION}

Management of patients with mandibular tumors includes segmental mandibulectomy with or without adjuvant therapy.[1] This surgical intervention creates a discontinuity defect in the mandible, causing the functional and esthetic deficit.[2] As a result, the mandible is often surgically reconstructed utilizing an osteocutaneous free flap to attain satisfactory facial contour, acceptable esthetics, and reestablishment of oral function.[3] Postoperatively, patients may experience facial asymmetry and/or dental malocclusion, which may not be surgically correctable.[4, $\underline{5}]$ Direct occlusal modifications can be made to correct subtle discrepancies; however, severe dental malocclusion may require the fabrication of intraoral prosthetics. Fixed dental prosthetics may be possible for patients with intact dentition and appropriate skeletal relationships. For patients with severe postsurgical malocclusions, a removable maxillary occlusal splint can be fabricated that serves to establish the occlusion between the maxillary and mandibular arches. At present, there is limited literature on the role of a maxillary occlusal splint for the surgically reconstructed 
mandibulectomy patient in the management of postsurgical malocclusion. The purpose of this report is to describe the fabrication of maxillary occlusal splint prosthesis for the management of postsurgical malocclusion in the surgically reconstructed mandibulectomy patient.

\section{Prosthesis Fabrication TEChNIQUe}

The patient is referred to the restorative dentist by the head and neck reconstructive surgeon for the fabrication of the maxillary occlusal splint. A clinical and radiographic evaluation is completed to confirm that the maxillary teeth are suitable for retaining a maxillary prosthesis as well as to confirm that the jaws are without additional pathology [ Figure 1]. The process for fabrication is reviewed, and the patient is counseled that the prosthesis may be used during speech and/or mastication as needed. To fabricate the prosthesis, maxillary and mandibular impressions are made with irreversible hydrocolloid impression material (Jeltrate Plus; Dentsply Sirona, York, PA). A maxillary cast is poured using dental stone (Type III, Denstone, Modern Materials; Kulzer, LLC, South Bend, IN) and an acrylic processed base is fabricated (Lucitone 199; Dentsply Sirona, York, PA) [igure 2a] with wrought wire and ball clasps for retention. Occlusal contacts are then generated intraorally on the acrylic processed base with greenstick impression compound (Kerr, SpofaDental, Jicin, Czech Republic) [ $\underline{\text { Figure 2b] }}$. The prosthesis is then processed secondarily with acrylic resin (Lucitone 199; Dentsply Sirona, York, PA) [igure 3]. Occlusion is then confirmed intraorally, the prosthesis is polished, and delivered [Figure $\underline{4 a}$ and $\underline{b}$ ]. Home care instructions are reviewed, including fluoride supplementation with a 5000-ppm fluoride dentifrice, and the patient is counseled to follow-up on a 3-month interval.

\section{Discussion}

Postoperative malocclusion is a sequela of reconstructive surgery that may not be self-resolving or surgically reversible. As a result, prosthodontic ingenuity may be a potential approach to manage such an issue. The maxillary occlusal splint allows the reestablishment of the occlusal contacts with limited chair time for fabrication. In addition, this approach is reversible and inexpensive to both the patient and the provider. Moreover, this solution may be a suitable alternative approach to care for patients that may be unable to afford conventional fixed prosthodontic treatment.[] Long-term success is dependent on patient oral hygiene maintenance for retention of abutment teeth. Limitations of this approach include access to a prosthodontist or dentist with knowledge of this procedure as well as access to a laboratory capable of prosthesis fabrication.

\section{SUMMARY}

The maxillary occlusal splint is a reversible expeditious treatment option to manage postsurgical malocclusion following mandibular osteocutaneous free flap reconstruction. This treatment approach can be utilized to manage a nonsurgically correctable and nonself-resolving malocclusion following oncologic therapy for the head-and-neck surgical patient.

\section{Financial support and sponsorship}

Nil.

\section{Conflicts of interest}

There are no conflicts of interest.

\section{REFERENCES}


Maxillary Occlusal Splint Following Segmental Mandibulectomy and Osteocutaneous Free Flap Reconstruction - A Case Report

1. Petrovic I, Ahmed ZU, Huryn JM, Nelson J, Allen RJ, Jr, Matros E. Oral rehabilitation for patients with marginal and segmental mandibulectomy: A retrospective review of 111 mandibular resection prostheses. $J$ Prosthet Dent. 2019 pii: S0022-3913(18)30910-7. [PMCID: PMC6599720] [PubMed: 30782457]

2. Rogers SN. Quality of life perspectives in patients with oral cancer. Oral Oncol. 2010;46:445-7. [PubMed: 20308002]

3. Nocini PF, Chiarini L, Fior A, Bedogni A. Le Fort I osteotomy to correct malocclusion after reconstruction of the maxilla with the free fibula flap. J Craniofac Surg. 2009;20:1420-3. [PubMed: 19816271]

4. Chang YM, Chana JS, Wei FC, Tsai CY, Chen SH. Osteotomy to treat malocclusion following reconstruction of the mandible with the free fibula flap. Plast Reconstr Surg. 2003;112:31-6. [PubMed: 12832873]

5. Tan BK, Por YC, Chen HC. Complications of head and neck reconstruction and their treatment. Semin Plast Surg. 2010;24:288-98. [PMCID: PMC3324233] [PubMed: 22550450]

6. Graser GN, Rogoff GS. Removable partial overdentures. Dent Clin North Am. 1990;34:741. [PubMed: 2227044]

Figures and Tables 


\section{Figure 1}

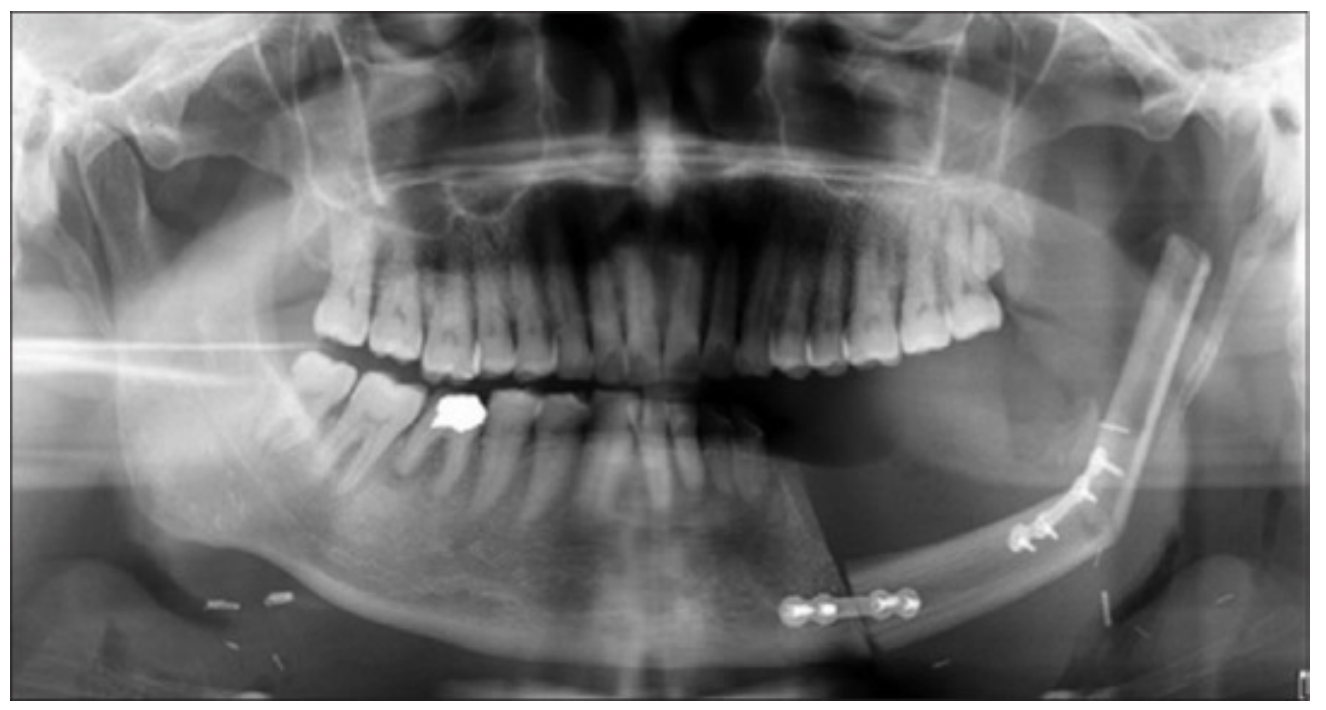

Panoramic radiograph of reconstructed mandible with fibula free flap 
Figure 2
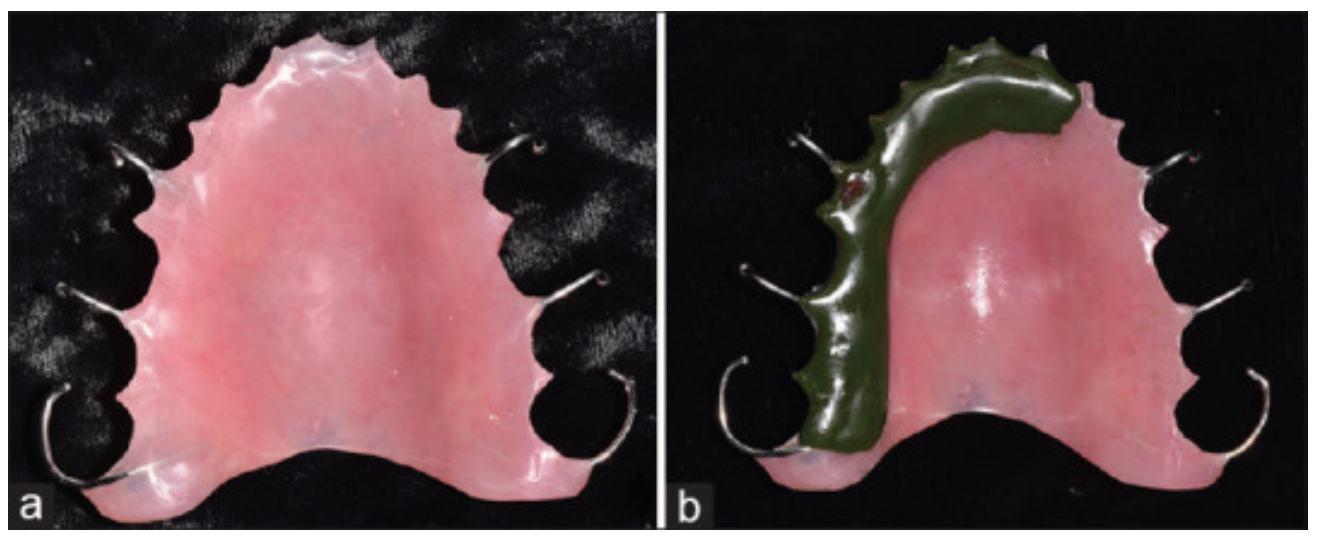

(a) Maxillary acrylic processed base. (b) Maxillary acrylic processed base with impression compound reestablishing occlusal contacts 


\section{Figure 3}

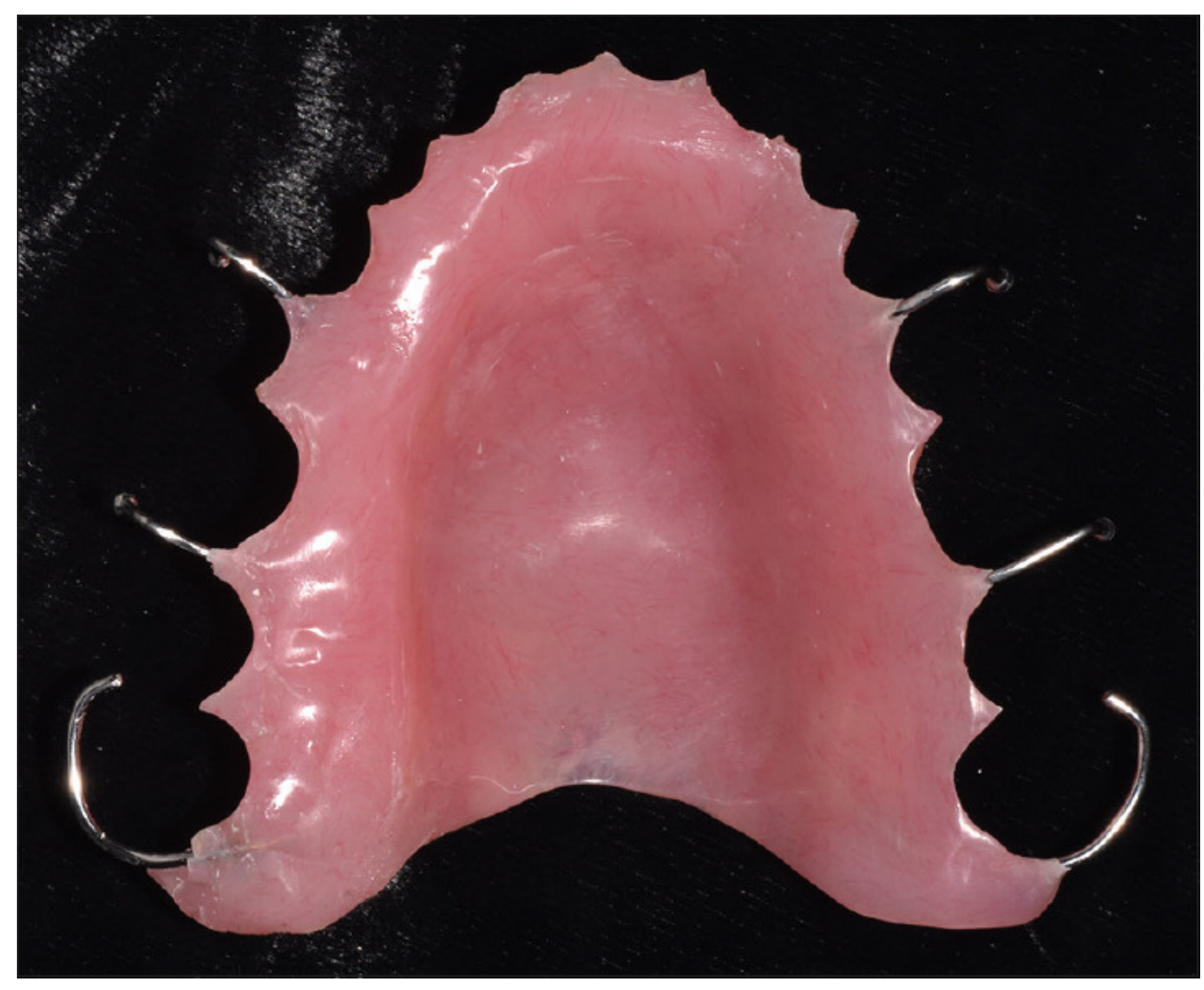

Maxillary occlusal splint 
Figure 4

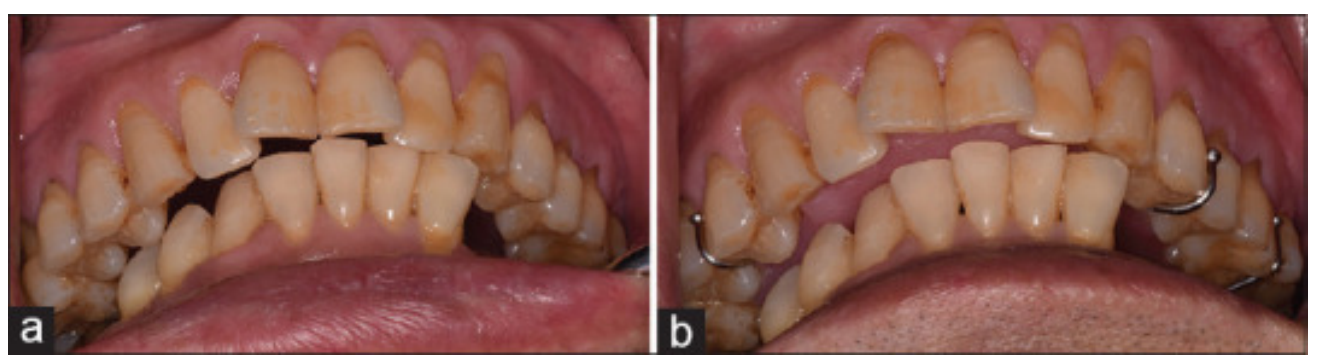

(a and b) Postoperative intraoral retracted view without and with maxillary occlusal splint

Articles from Annals of Maxillofacial Surgery are provided here courtesy of Wolters Kluwer -- Medknow Publications 